\title{
Fake News and Indifference to Truth: Dissecting Tweets and State of the Union Addresses by Presidents Obama and Trump
}

\author{
David E. Allen \\ School of Mathematics and Statistics, University of Sydney, Australia, Department of \\ Finance, Asia University, Taiwan, and School of Business and Law, Edith Cowan \\ University, Western Australia

\section{Michael McAleer} \\ Department of Finance, Asia University, Taiwan, Discipline of Business Analytics, \\ University of Sydney Business School, Australia, Institute of Advance Studies, Yokohama \\ National University, Japan, and Econometric Institute, Erasmus School of Economics, \\ Erasmus University Rotterdam, The Netherlands, and Department of Economic Analysis \\ and ICAE, Complutense University of Madrid, Spain
}

\section{David McHardy Reid}

Albers School of Business and Economics, Seattle University, Washington, USA

\begin{abstract}
State of the Union Addresses (SOUA) by two recent US Presidents, President Obama (2016) and President Trump (2018), and a series of recent of tweets by President Trump, are analysed by means of the data mining technique, sentiment analysis. The intention is to explore the contents and sentiments of the messages contained, the degree to which they di_er, and their potential implications for the national mood and state of the economy. President Trump's 2018 SOUA and his sample tweets are identi_ed as being more positive in sentiment than President Obama's 2016 SOUA. This is con_rmed by bootstrapped t tests and non-parametric sign tests on components of the respective sentiment scores. The issue of whether overly positive pronouncements amount to self-promotion, rather than intrinsic merit or sentiment, is a topic for future research.
\end{abstract}

Keywords Sentiment Analysis, Polarity, Bootstrapped t tests, Sign tests,
JEL Classification
A1, C88, C44, Z0.

\section{Working Paper no 1807 \\ March, 2018}




\title{
Fake News and Indifference to Truth: Dissecting Tweets and State of the Union Addresses by Presidents Obama and Trump
}

\author{
David E. Allen ${ }^{\mathrm{a}, *}$, Michael McAleer ${ }^{\mathrm{b}}$, David McHardy Reid ${ }^{\mathrm{c}}$ \\ ${ }^{a}$ School of Mathematics and Statistics, University of Sydney, Australia, Department of \\ Finance, Asia University, Taiwan, and School of Business and Law, Edith Cowan \\ University, Western Australia \\ ${ }^{b}$ Department of Finance, Asia University, Taiwan, Discipline of Business Analytics, \\ University of Sydney Business School, Australia, Institute of Advance Studies, Yokohama \\ National University, Japan, and Econometric Institute, Erasmus School of Economics, \\ Erasmus University Rotterdam, The Netherlands, and Department of Economic Analysis \\ and ICAE, Complutense University of Madrid, Spain \\ ${ }^{c}$ Albers School of Business and Economics, Seattle University, Washington, USA
}

\begin{abstract}
State of the Union Addresses (SOUA) by two recent US Presidents, President Obama (2016) and President Trump (2018), and a series of recent of tweets by President Trump, are analysed by means of the data mining technique, sentiment analysis. The intention is to explore the contents and sentiments of the messages contained, the degree to which they differ, and their potential implications for the national mood and state of the economy. President Trump's 2018 SOUA and his sample tweets are identified as being more positive in sentiment than President Obama's 2016 SOUA. This is confirmed by bootstrapped t tests and non-parametric sign tests on components of the respective sentiment scores. The issue of whether overly positive pronouncements amount to self-promotion, rather than intrinsic merit or sentiment, is a topic for future research.
\end{abstract}

Keywords: Sentiment Analysis, Polarity, Bootstrapped t tests, Sign tests, JEL Codes: A1, C88, C44, Z0.

«The analysis in the paper was undertaken with the $R$ sentiment package. Acknowledgements: For financial support, the first author acknowledges the Australian Research Council, and the second author is most grateful to the Australian Research Council, National Science Council, Ministry of Science and Technology (MOST), Taiwan, and the Japan Society for the Promotion of Science.

*Corresponding author.

Email address: profallen2007@gmail.com 


\section{George Costanza:}

\section{"Jerry, just remember, it's not a lie if you believe it."}

\section{Introduction}

In early 2018 US President Trump announced 'Fake News Awards' and thereby continued his questioning of the accuracy of the media. The President used Twitter to announce the "winners", most frequently naming the New York Times and CNN for a series of transgressions which varied from minor errors by journalists on social media to news reports that later invited corrections. Given his predilection for criticising the media, the authors thought it might be of interest to subject some of his own prounouncements to textual analysis using data mining techniques. We decided to analyse his 2018 State of the Union Address (SOUA), a series of 10 days of recent tweets, running from 19 January 2018 to 29 January 2018 plus, as a means of providing a contrasting benchmark, President Obama's 2016 SOUA.

The contents of these are analysed using the $\mathrm{R}$ package 'sentiment'. Data mining refers to the process of analysing data sets to reveal patterns, and usually involves methods that are drawn from statistics, machine learning, and database systems. Text data mining similarly involves the analysis of patterns in text data. Sentiment analysis is concerned with the emotional context of a text, and seeks to infer whether a section of text is positive or negative, or the nature of the emotions involved. There is a variety of methods and dictionaries that exist for undertaking sentiment analysis of a piece of text.

Although sentiment is often framed in terms of being a binary distinction (positive versus negative), it can also be analysed in a more nuanced manner. We decided to apply the R package 'sentiment', which distinguishes between five different emotions, namely joy, sadness, anger, fear and surprise. There are many different forms of sentiment analysis, but many use the same basic approach. They begin by constructing a list of words or dictionary associated with different emotions, count the number of positive and negative words in a given text, and then analyse the mix of positive and negative words to assess the general emotional tenor of the text.

Linear thinking is the enemy of the political victor (Reid, 1988). We recognize that in the context where political persuasion occurs, based essentially on words and emotions, that words are not the only medium and this may be a limitation of any study. The immediacy of language can be influential in persuasion (Wiener and Mehrabian, 1968). Words may be overpowered by other non-verbal cues, such as the tone of voice and facial expression (Mehrabian, 1981). McLuhan (1964) proposes that the media, as opposed to the content that they carry, affect society by way of its characteristics rather than its content. With Twitter there is a new medium, and Trump's style of presentation constitutes a break from tradition. The combination makes an influential impact. By targeting specific segments of the voting population, he may, as Swartz 
(1973) suggests, be providing an effective set of stimuli that serves to hook deeply rooted sensations and beliefs.

Clearly, there are considerable limitations to the basic approach adopted in the paper. Pröllochs et al. (2017) discuss the difficulties in processing negations, which invert the meanings of words and sentences. Equally problematic are sarcasm, backhanded compliments, and inflammatory gibberish, such as "Little Rocket Man" and "Crooked Hillary", in the context of President Trump's tweets. Nevertheless, sentiment analysis can reveal the general emotional direction of a piece of text, and machine-based learning systems are well established methods for the sifting and interpretation of digital information. This tool has numerous applications in, for example, financial markets.

Keynes (1936) made a famous and prescient analogy between choosing investment stocks and a fictional newspaper beauty competition, in which entrants are asked to choose from a set of six photographs of women that are the most beautiful. Those who picked the most popular face would then be eligible for a prize. "It is not a case of choosing those [faces] that, to the best of one's judgment, are really the prettiest, nor even those that average opinion genuinely thinks the prettiest. We have reached the third degree where we devote our intelligences to anticipating what average opinion expects the average opinion to be. And there are some, I believe, who practice the fourth, fifth and higher degrees." (Keynes (1936), Chapter 12, p.100). We can now apply machine learning techniques to news feeds to determine what average opinion is.

For example, the Thomson Reuters News Analytics (TRNA) series could be termed news sentiment, and is produced by the application of machine learning techniques to news items. The TRNA system can scan and analyse stories on thousands of companies in real time, and translate the results into a series that can be used to help model and inform quantitative trading strategies. RavenPack is another example of a commercial news analytics product with applications to financial markets. There is now considerable evidence about the commercial relevance of financial news analysed using machine learning methods.

Allen, McAleer and Singh $(2015,2017)$ analyse the economic impact of the TRNA sentiment series. The first of these papers examines the influence of the Sentiment measure as a factor in pricing DJIA constituent company stocks in a Capital Asset Pricing Model (CAPM) context. The second uses these real time scores, aggregated into a DJIA market sentiment score, to analyse the relationship between financial news sentiment scores and the DJIA return series, using entropy-based measures. Both studies find that the sentiment scores have a significant information component which, in the former, is priced as a factor in an asset pricing context.

Other research on this topic argues that news items from different sources influence investor sentiment, which feeds into asset prices, asset price volatility and risk (see, among others, Tetlock (2007), Tetlock, Macskassy and SaarTsechansky (2008), Da, Engleberg and Gao, (2011), Barber and Odean (2008), diBartolomeo and Warrick (2005), Mitra, Mitra and diBartolomeo (2009), and Dzielinski, Rieger and Talpsepp (2011)). The diversification benefits of the in- 
formation impounded in news sentiment scores provided by RavenPack have been demonstrated by Cahan, Jussa and Luo (2009), and Hafez and Xie (2012), who examined the benefits in the context of popular asset pricing models.

However, in the current paper the focus is on the actual content of President Obama's 2016 SOUA, President Trump's 2018 SOUA, and a sample of President Trump's 2018 tweets. The intention is to explore whether there are any systematic differences in the sentiments of the two president's outputs, and whether there is any evidence of a tendency by President Trump to give a 'positive' spin for the benefit of his voter base, previously dubbed the 'deplorables' by the former US Secretary of State and rival Presidential candidate, Hillary Rodham Clinton.

The paper is divided into four sections. An explanation of the research method is given in Section 2, Section 3 presents the results, and Section 4 provides a brief conclusion.

\section{Research Method}

The analysis features the use of an R library package which facilitates sentiment analysis, 'sentiment'. The 'sentiment' package was written by Dvries (2012), is now archived from the current release of R, and has to be loaded from 'Github.com'. It is a dictionary-based method which calculates sentiment scores using affinity dictionaries. The program splits strings into words (by default at space), looks up an affinity score for each word, and returns the average, using a scale from +5 to -5 . The authors apply this package because it is more finely grained and categorizes five different sentiment emotions, namely joy, sadness, anger, fear and surprise, and reveals greater information about the emotional tenor of the text or string that is analysed.

We also experimented with the 'Sentiment Analysis' package from the $\mathrm{R}$ library that was released on the Cran R repository in 2017 by Feuerriegel and Pröllochs. This package features use of opinion mining to extract the polarity of the expressed opinion in a range spanning from positive to negative. The package implementation uses various existing dictionaries, such as QDAP or Loughran-McDonald, but also provides a facility to generate purpose-built dictionaries. However, for current purposes, we preferred the analysis provided by the 'sentiment' package.

The process of performing sentiment analysis requires textual input in a machine-readable format. Pre-processing is required to turn the text into single words, followed by what are common pre-processing steps: stopword removal, stemming, removal of punctuation, and conversion to lower-case. This was an issue, in particular, for President Trump's twitter feeds. In the application of the 'Sentiment Analysis' package, we tried adopting a binary framework which permitted the computation of the polarity of a document on a scale from very positive to very negative. However, the categories are not further distinguished or rated, such that all positive words are assigned the same degree of positivity. The binary analysis factor has two levels, indicating positive and negative 
content. It should be borne in mind that neutral documents, or strings (with a sentiment score of 0 ), are counted as positive.

We decided that the more finely grained analysis permitted by the 'sentiment' package are more informative, and report the results of the analysis, as applied to the three sample texts. The President Obama 2016 SOUA in its machine-readable form has 6099 words and 34,729 characters. The President Trump 2018 SOUA has 1683 words and 10,131 characters, so it is roughly onethird the size of the Obama SOUA. The series of 10 days of tweets by President Trump, from 19 January to 29 January 2018, comprise 1683 words and 10,128 characters, so that the latter two sets of text have almost identical size.

The limitations of the analysis should be borne in mind. The context of 'natural language processing', of which sentiment analysis is a component, is important. The use of sarcasm and other types of ironic language are inherently problematic for machines to detect, when viewed in isolation. This is a potential issue, in particular, in the analysis of President Trump's tweets. Nevertheless, current methods are revealing, as will be seen in the next section which presents the results.

\subsection{Results of the Analysis}

We commence with the results of the application of the sentiment package to President Trump's 2018 SOUA. The emotional content of the address is shown in Figure 1.

Ignoring the 'unknown' category, the predominant emotion recognised in Figure 1 is 'joy', followed by 'anger', 'fear' and 'surprise', all at very low levels. Almost 50 per cent of the address is not classified, but 20 per cent is classified as being 'joy', which is a positive emotion. Figure 2 classifies the text of Trump 2018 SOUA according to whether it is negative, neutral or positive. In excess of 60 per cent of the classification in Figure 2 is positive.

Figure 3 shows a word cloud analysis of Trump's 2018 SOUA. A word cloud is another form of visual representation of text data in which tags are single words, and their relative size and colour represent their weighting or importance in the context of the text considered.

The most prominent words in the word cloud in Figure 3 are 'welcome', 'thank' and 'wonderful'. If we move around the cloud in an anti-clockwise manner, words in the 'joy' section include 'strong', 'happy', 'security','economy', 'services', 'policy', and so forth. In the 'anger' section below, we have 'murder', 'holocaust', 'genocide', 'victims', 'shooting', and so on. In the 'fear' section, we see 'deferred', 'pathway', 'citizenship', 'childhood arrivals', and so on. There are no words in the suprise section, which was the smallest category, while the unknown is the largest section, with a diverse grouping of words, with none given noticeable prominence.

We then analyse the tweets from 19 January to 29 January 2018. These tend to be governed by what President Trump momentarily deemed to be the issues demanding his attention in that ten-day period. 'DACA' (Direct Action on Childhood Arrivals) received attention, as did the 'wall', Afghanistan, following Taliban bombings, Holocaust Remembrance Day, and the Border Patrol 
Figure 1: TRUMP 2018 SOUA SENTIMENT

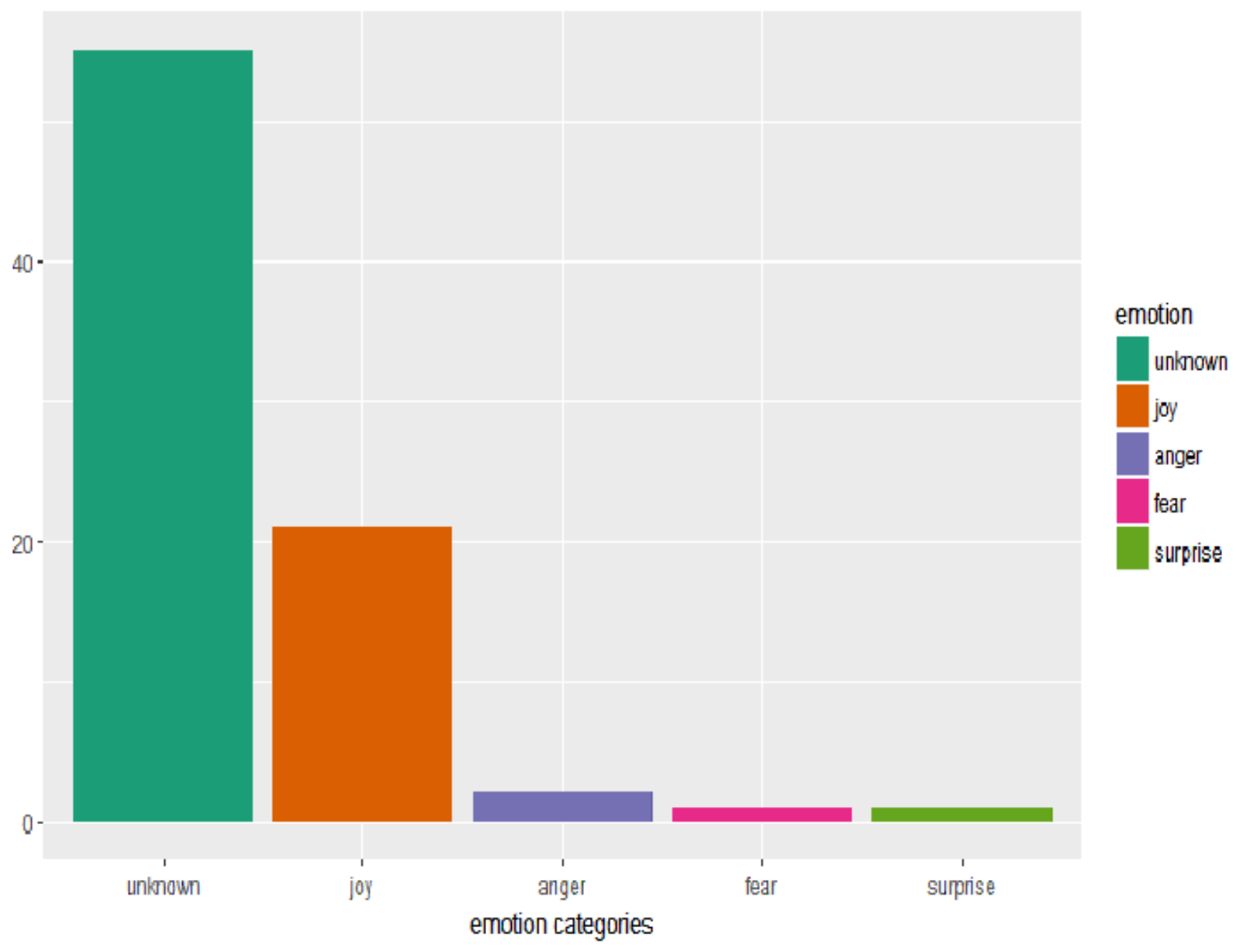


Figure 2: TRUMP 2018 SOUA SENTIMENT POLARITY

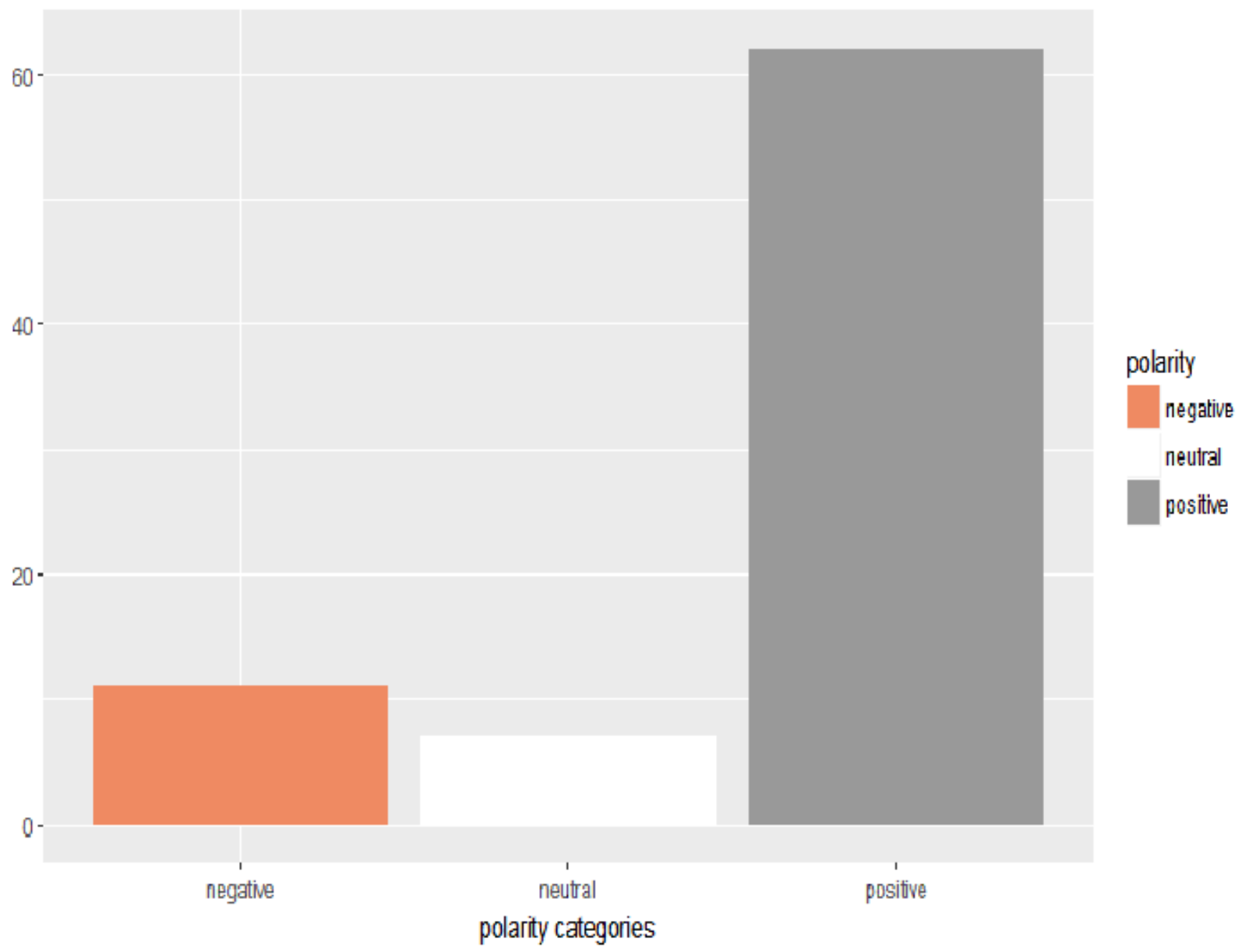


Figure 3: TRUMP 2018 SOUA WORD CLOUD

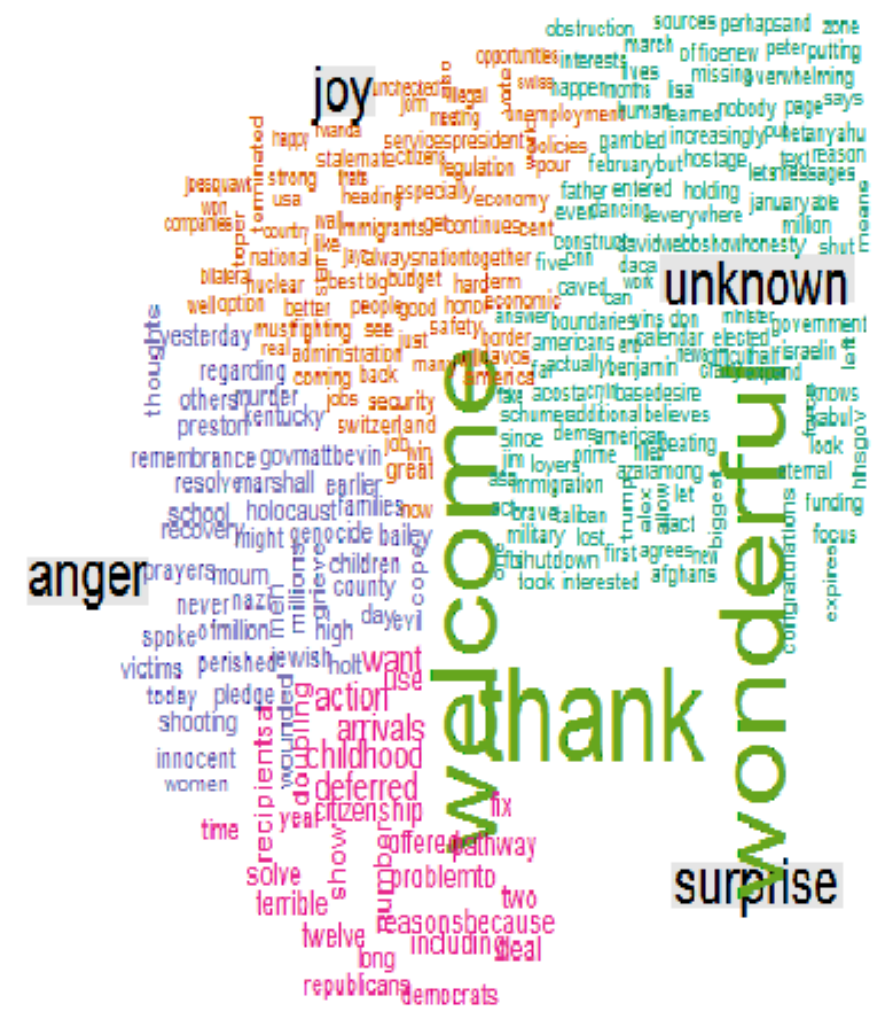

fear 
Figure 4: TRUMP TWEETS SENTIMENT

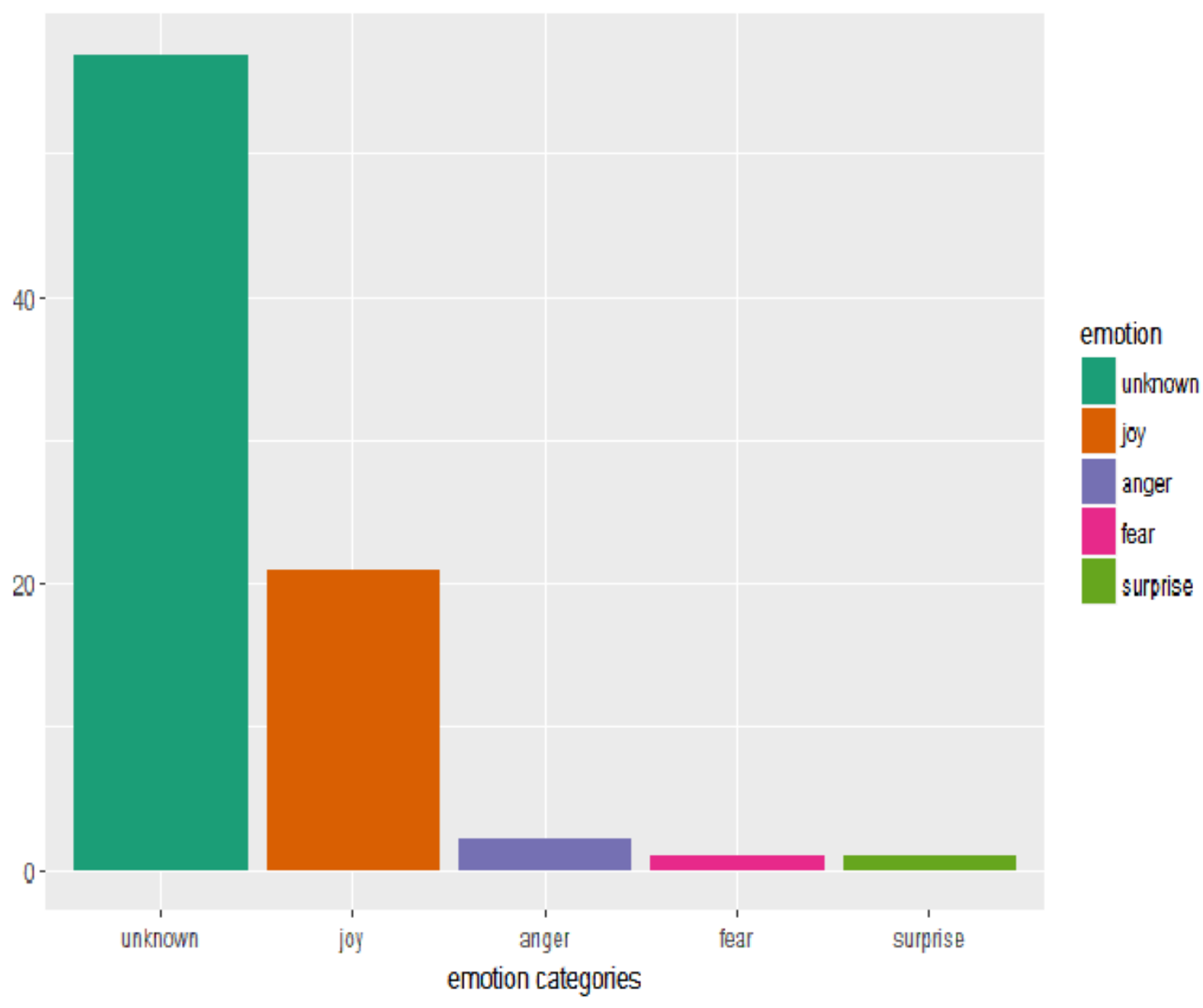


Figure 5: TRUMP TWEETS SENTIMENT POLARITY

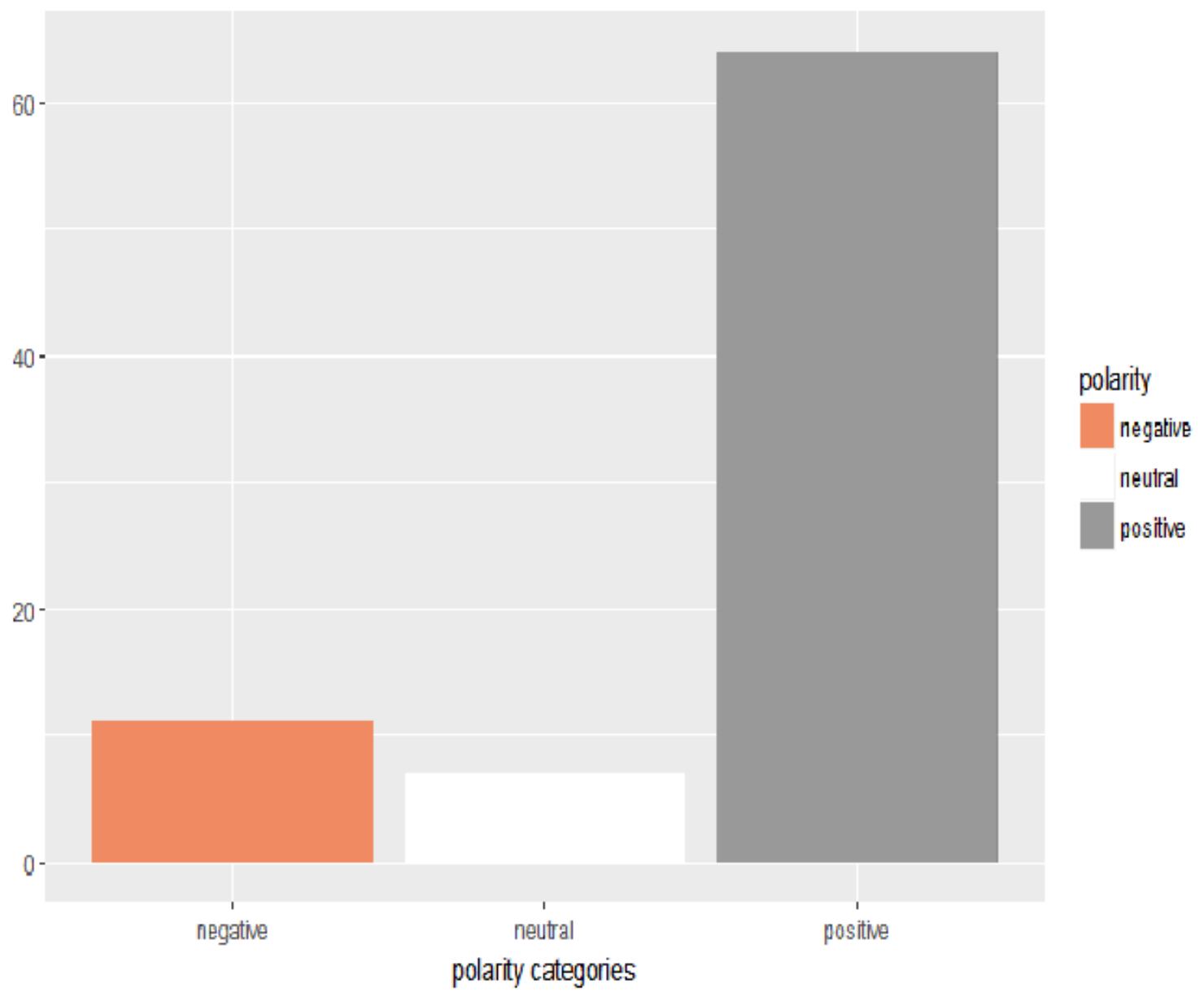


Figure 6: TRUMP TWEETS WORD CLOUD

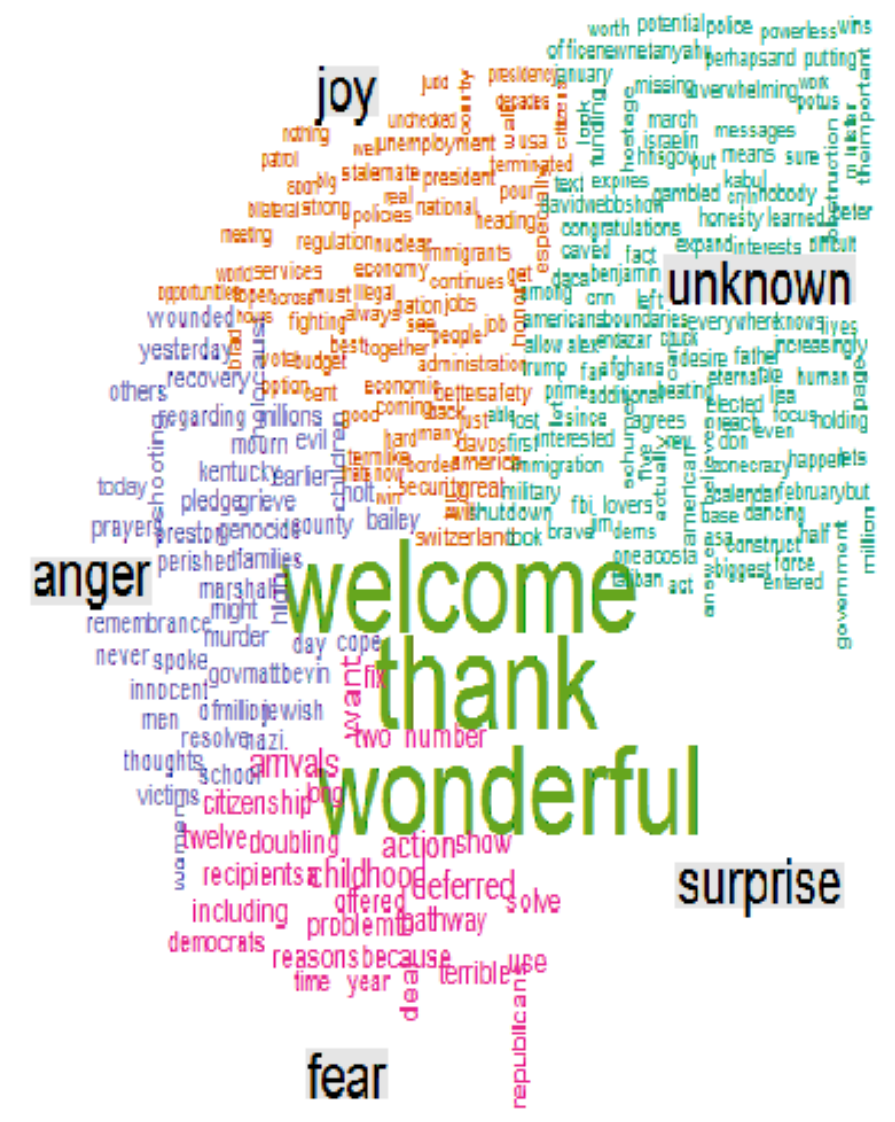




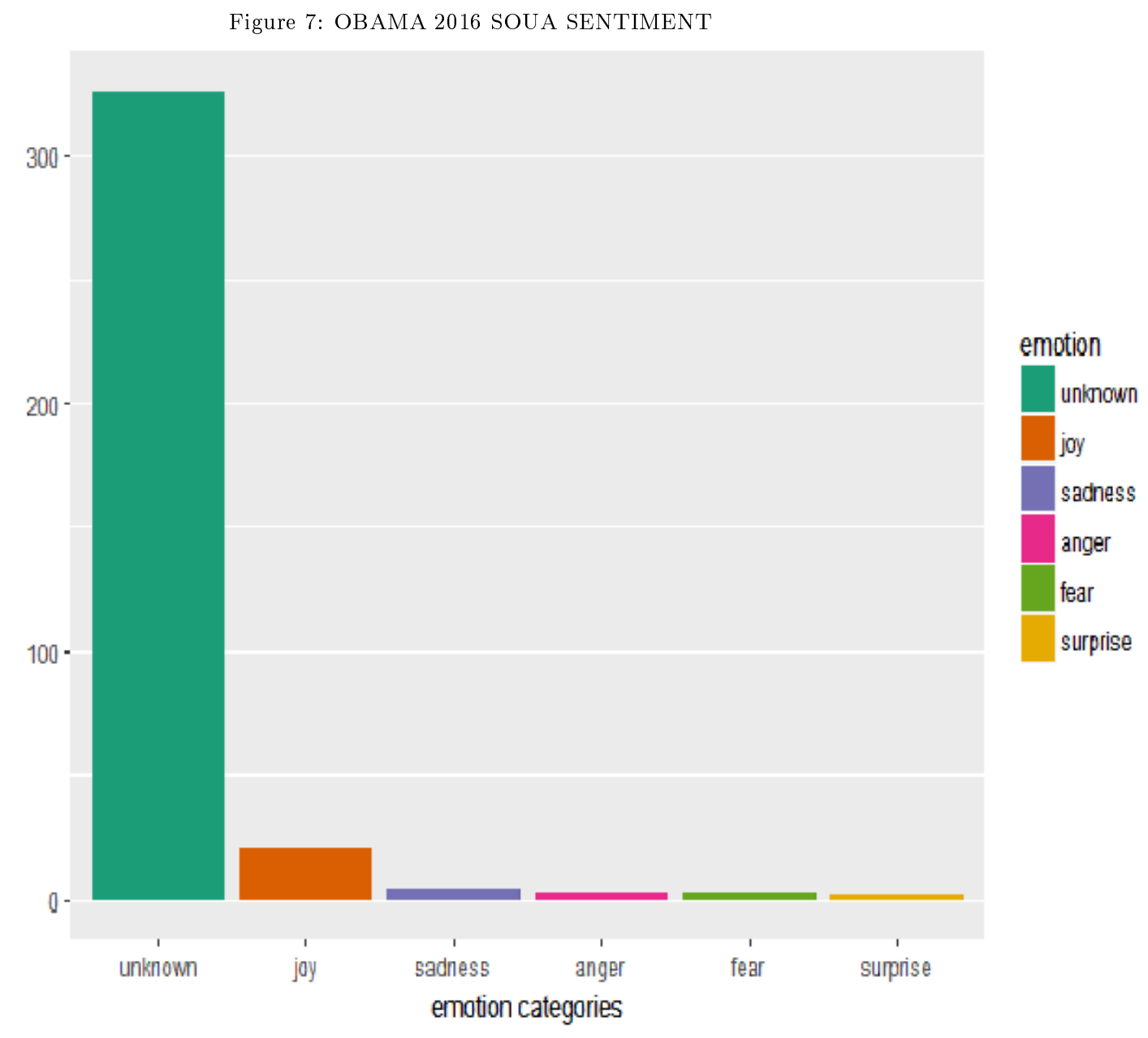


Council. This period coincided with his attendance at DAVOS 2018, so there are numerous relevant tweets. There was also mention of 'Cryin Chuck Schumer' and 'Crazy Jim Acosta of Fake News CNN', but we are not sure what the textual analysis would make of this type of sarcasm. Another major topic was the brief government shutdown. The results of the sentiment analysis of these tweets are shown in Figure 4.

The results show, that once again, 'joy' is the most frequently recognised emotion, followed by 'anger', 'fear' and 'surprise', at much lower frequencies. Figure 5 depicts the division of the emotions into positive and negative binary responses.

The results again show a predominance of positive categories, measuring above sixty per cent of the sentiment successfully ascribed, which is similar to the proportions noted in the TRUMP 2018 SOUA. Negative sentiments are of a similar order, at just above 10 per cent. The results show that, once again, 'joy' is the most frequently recognised emotion, followed by 'anger', 'fear' and 'surprise', at much lower frequencies.

Figure 6 presents a word cloud analysis of the Trump tweets, in which the most prominent words are 'welcome', 'thank', and 'wonderful', which suggests that these are key Trump phrases. If we examine the cloud, as previously, in an anti-clockwise manner, beginning with 'joy', we see 'regulation', 'economy', 'administration', 'immigrants', 'services', 'policy', 'unchecked', 'access', 'jobs', and so on. The category 'anger' includes 'wounded', 'recovery', 'kentucky', 'pledge' 'prayer', 'remembrance', 'marshall', 'genocide', 'victims', and so on. The category 'fear' includes 'democrats', 'arrivals', 'citizenship', 'childhood' and 'deferred' (presumably a reference to DACA), 'terrible', 'number', and so forth. There are no words noted under 'surprise', and 'unknown' has the largest component of words that the program could not categorize.

By way of contrast, and to provide an alternative SOUA address benchmark, we also analyse the President Obama 2016 SOUA, where Figure 7 provides the results of a sentiment analysis.

It is noticeable in Figure 7 that, although the emotion 'joy' predominates, it is not to the same extent as in the previous analysis of the Trump 2018 SOUA and tweets. This is reinforced by the analysis depicted in Figure 8, which reveals that the predominant sentiment in Obama 2016 SOUA is negative, by an extremely large margin. 
Figure 8: OBAMA 2016 SOUA SENTIMENT POLARITY

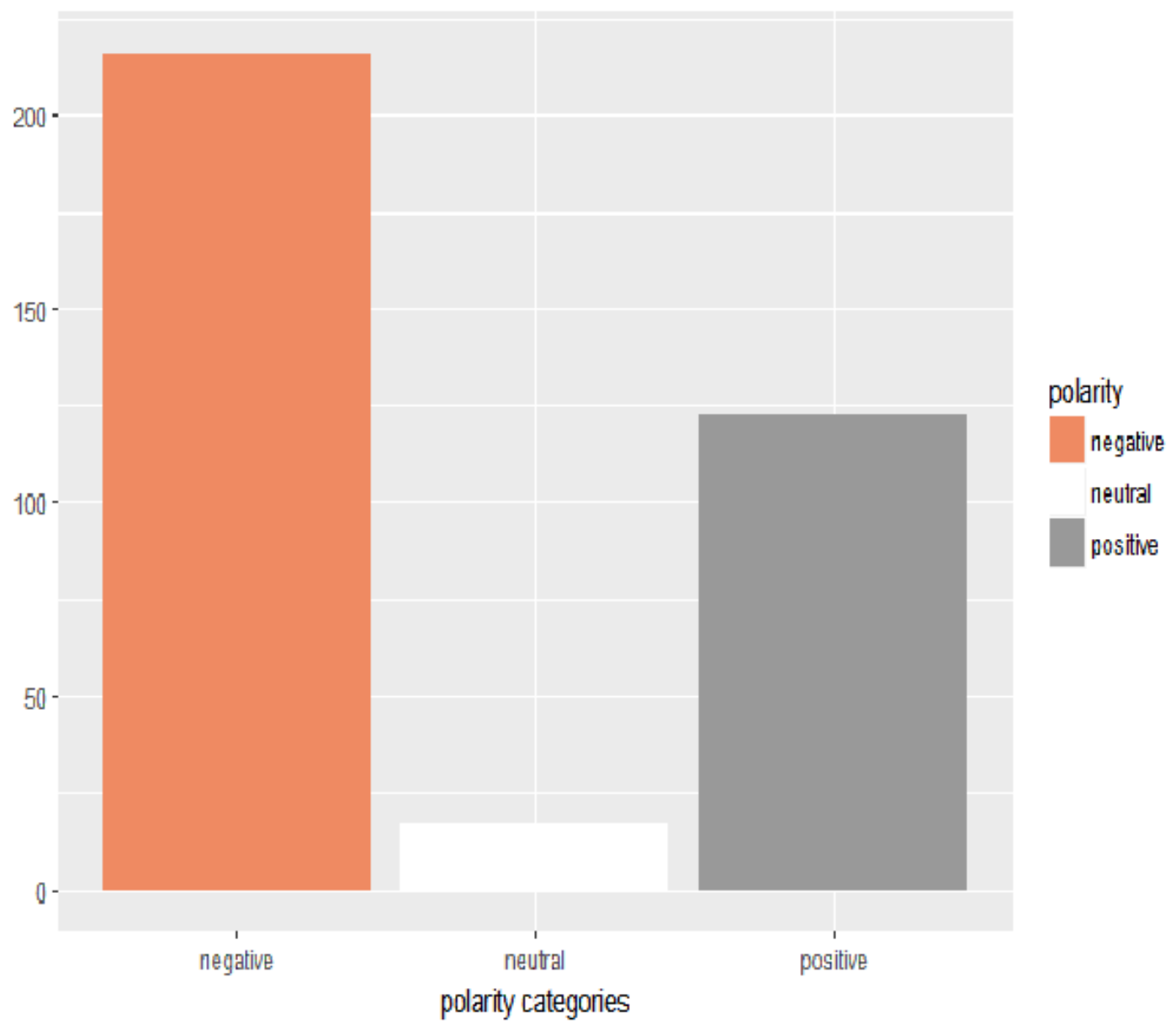


Figure 9: OBAMA 2016 SOUA WORD CLOUD

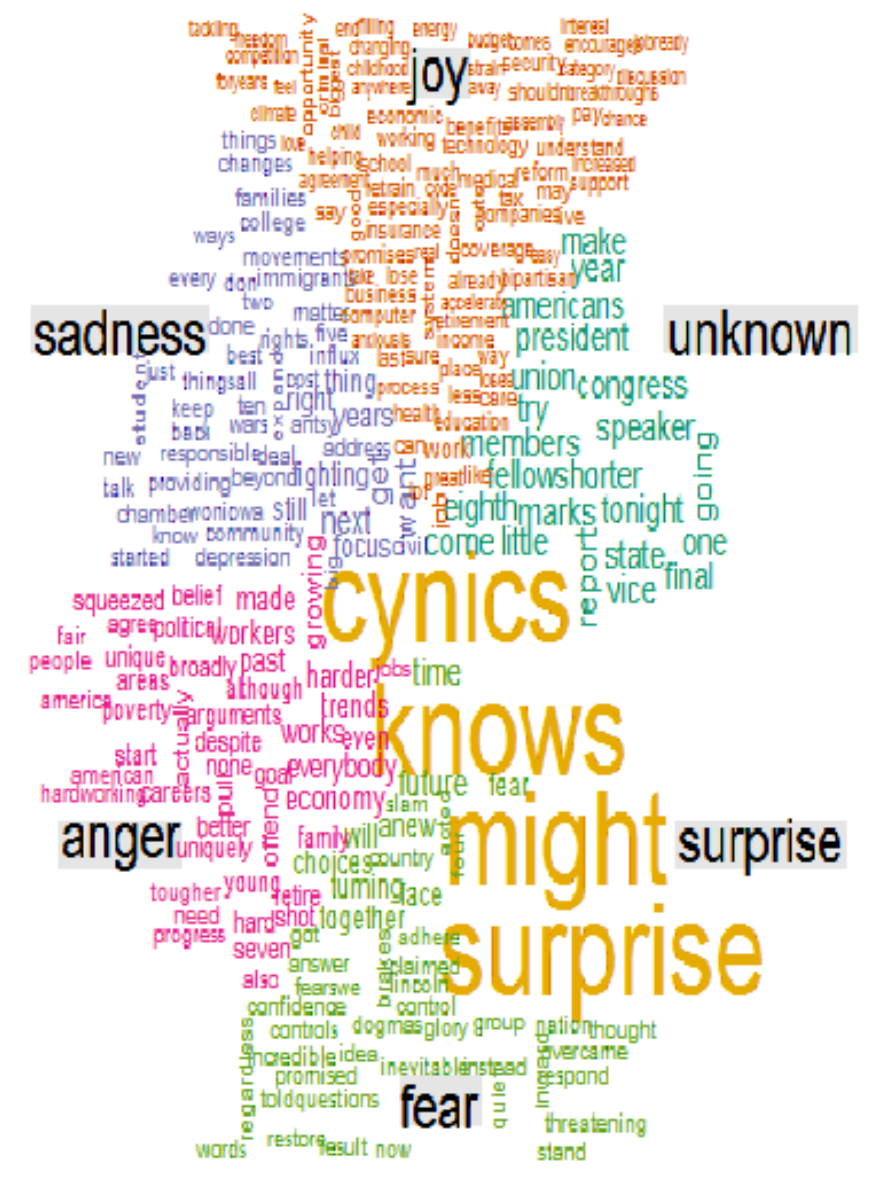


The word cloud presented in Figure 9 for Obama 2016 SOUA reveals that the most frequently occurring words are 'cynics', 'knows', 'might' and 'surprise'. If we examine the cloud, beginning with the emotion 'joy' and moving in an anti-clockwise manner, we see under 'joy' the words 'economic', 'changing', 'energy', 'budget', technology', 'school', 'retrain', 'tax' , 'education', 'insurance','computer', 'health', and so on.

Under the rubric 'sadness', we note the words 'families', 'college', 'influx', 'immigrants', 'rights', 'cost', 'community', 'depression', 'years', 'fighting', 'focus', 'want', and so on. Under 'anger', the words 'squeeze', 'belief', 'poverty', 'workers', 'jobs', 'shot', 'economy', 'tougher', and 'retire' are prominent.

The emotion 'fear' suggests the words 'future', 'fear', 'country', 'control', 'lincoln', 'threatening', 'restore', 'promised', 'dogmas', 'questions', and 'nation', to cover a selection. There is nothing mentioned in the category 'surprise', and the rest of the classification is 'unknown'.

Thus the tenor of the Obama 2016 SOUA is very different from both the Trump 2018 SOUA and his pronouncements via his twitter feed. It is predominantly negative, as opposed to positive.

There is some limited evidence that Obama's 2016 SOUA is not typical of previous democratic SOUAs. Tatman (2017) provides an online analysis of the 1989-2017 SOUAs (see: https://www.kaggle.com/rtatman/tutorial-sentimentanalysis-in-r, accessed 4/2/2018). This analysis has been undertaken using different $\mathrm{R}$ packages, including 'tidyverse' and tidytext', so the metrics may not be identical to those used in this paper, but the implications of the analysis are clear. This analysis provides a comparison of the sentiment of SOUAs along party lines, which is reproduced in Figure 10.

The plot in Figure 10 suggests that the more customary pattern is for Democratic SOUAs to be more positive, in sentiment terms, than their Republican counterparts. The Obama versus Trump comparison reverses this relationship, where Trump is considerably more positive. In the next sub-section, we provide some formal tests of the Obama and Trump sentiment scores.

\subsection{Sign and bootstrapped $t$ tests}

Obama 2016 SOUA is roughly three times the length of TRUMP 2018 SOUA. The main result of the sentiment analysis was that the Trump sentiment was more positive than the Obama sentiment. We use a boot-strapped $t$ test of the means of the two sample scores for 'joy' as a direct test. Obama 2016 SOUA analysis had 'joy' scores for 356 strings, whereas Trump 2018 SOUA only had scores for 80 strings. We used 1000 samples with replacement to undertake a bootstrapped $t$ test of the difference in the two means. The results are shown in Table 1. 
Figure 10: ANALYSIS OF 1989-2016 SOUAs ALONG PARTY LINES

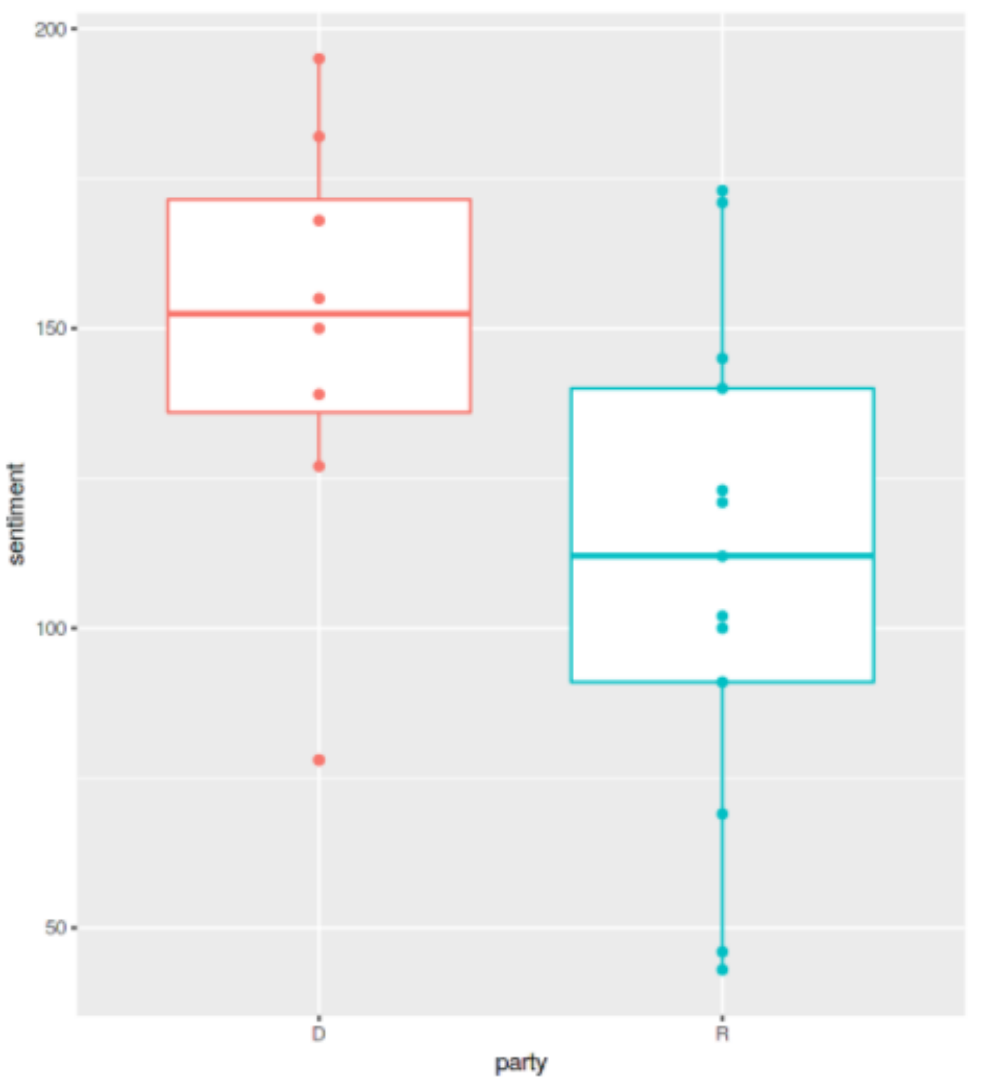

party
क्षे
क्षे

ource: R. Tatman, https://www.kaggle.com/rtatman/tutorial-sentiment-analysis-in-r 
As suspected, according to the bootstrapped t test, the Trump 2018 SOUA 'joy' score is significantly higher than the Obama 2016 SOUA 'joy' score. The mean $\mathrm{t}$ value is -3.553 , with a mean probability of 0.0043 .

We also undertook non-parametric sign tests of the differences in the sentiment scores in the individual SOUA texts. This test is based on the fact that, if two samples, $x$ and $y$, are drawn randomly from the same distribution, the probability that $x_{i}>y_{i}$, for each observation $i$, should equal 0.5 . The test statistic is $w$, the number of observations for which $x_{i}>y_{i}$. Under the null hypothesis this follows the Binomial distribution with parameters $(n, 0.5)$, where $n$ is the number of observations.

Table 2 shows the results of a series of sign tests on sentiment. These suggest that there are significantly more negative than positive emotion scores in Obama 2016 SOUA, while it is reversed in Trump 2018 SOUA, which has significantly more positive sentiments, according to the sign test. These results suggest that, based on a comparison of the two SOUAs, President Trump tended to place a more positive gloss on the issues raised in their respective addresses than did President Obama.

The two Presidents did have a backdrop of different economic circumstances. In 2016 President Obama could point to the unemployment rate decling to a seven-year low of 5 per cent in October 2015, after soaring as high as 10 per cent in October 2009. He could also draw attention to a 106 per cent rise over the last seven years in the S\&P500 up to the time of his address. However, median hourly pay rose 7 per cent over the same seven years. Non-housing and student debt increased, while home ownership was reduced. There was also a reduction in the labour participation rate, exacerbated by the retirement of baby boomers and those dispirited people who elected to leave the workforce. At the same time, inequality grew, and wealth gains tended to be concentrated at the top end of the distribution.

President Trump's 2018 SOUA occurred one year later in the economic cycle. It is true that the unemployment rate in December 2017 was 4.1 per cent, which was a 17-year low around the country, and an 18-year low in some cities. This was also true for African Americans. The tax cut was large, but under 1 percent of GDP, and Ronald Reagan's was larger in 1981, at 2.89 per cent of GDP. It was, nevertheless, a significant legislative achievement. The stock market has boomed President Trump, until the very recent early 2018 correction but, as previously noted, was also expanding under President Obama. This has had a positive effect on '401k' retirement plans. President Trump has tried to repeal regulation and red tape, and significantly altered trade policy. Whether this leads to significant economic gains or losses remains to be seen.

\section{Conclusion}

The results of this paper featuring a sentiment analysis of the Obama 2016 SOUA, Trump 2018 SOUA, and a series of Trump tweets, are clear cut. The sentiment in President Trump's speech and tweets is much more positive than those in President Obama's SOUA. This also reverses the pattern in the relative 
sentiment scores of the Democrat versus Republican addresses since 1979. The differences in some of these scores was confirmed as being significant via some bootstrapped t tests and non-parametric sign tests.

Whether overly positive reporting is an effective strategy remains to be seen. President Trump is often criticised by political commentators as being selective with, or indifferent to, the 'truth', even though he regularly accuses media outlets of promoting 'fake news'. Is he himself, guilty of the same in his constant stream of positive sentiment tweets? Do they indeed amount to self-promotion?

The approach may form the basis of an effective communications strategy. Reid (1998) suggests that a politician cannot hope to appeal to all shades of political opinion. So first the strategy must begin with determining a "political complexion" that appeals to a critical mass of voters. This political complexion, in President Trump's case, features a postive tone embodied by the mantra "Make America Great Again", and sets the limits of an electoral appeal which resonates with fertile segments of the electorate.

These issues cannot effectively be addressed by means of sentiment analysis alone. What the current analysis can confirm is the relatively positive biases of both his 2018 SOUA and a sample of his tweets. The paper does not address the accuracy of his claims, or the effect that they may have on the broader economic and financial market sentiment. That remains a topic for future work. 
Table 1: Bootstrapped t test of the difference in means in Obama 2016 SOUA 'joy' mean and Trump 2018 SOUA 'joy'

\begin{tabular}{|c|c|c|c|}
\hline \multicolumn{4}{|c|}{ Obama SOUA 'joy' vs. Trump SOUA 'joy' } \\
\hline \hline mean t $=-3.553$, & mean p-value $=0.004293442$ & \\
\hline probability vect & 1st Quartile & median & 3rd Quartile \\
\hline probability & 0.0001175 & 0.0006358 & 0.0025725 \\
\hline t vector & -4.022 & -3.537 & -3.102 \\
\hline
\end{tabular}

Table 2: Non-parametric Sign Test Results

\begin{tabular}{|c|c|}
\hline Positive Trump 2018 SOUA v. Negative TRUMP 2018 SOUA \\
\hline \hline no. of differences & $\mathrm{n}=79$ \\
\hline no. of cases positive $>$ negative & $\mathrm{w}=68(86.08 \%)$ \\
\hline null hypothesis & $\mathrm{w}$ follows binomial $(79,0.5)$ \\
\hline & Prob(W $<=68)=1$ \\
\hline & Prob(W $>=68)=1.77228 \mathrm{e}-011$ \\
\hline Positive Obama SOUA 2016 & v. Negative Obama SOUA 2016 \\
\hline no. of differences & $\mathrm{n}=353$ \\
\hline no. of cases positive $>$ negative & $\mathrm{w}=137(38.81 \%)$ \\
\hline null hypothesis & $\mathrm{W}$ follows $\mathrm{B}(353,0.5)$ \\
\hline & Prob( $(\mathrm{W}=137)=1.53831 \mathrm{e}-005$ \\
\hline & Prob(W $>=137)=0.99999$ \\
\hline
\end{tabular}




\section{References}

[1] Allen, D.E., M. McAleer, and A.K. Singh (2015), Machine news and volatility: The Dow Jones Industrial Average and the TRNA real-time high frequency Sentiment Series, chapter 19 in Handbook of High Frequency Trading, Ed. G.N. Gregoriou, Elsevier, Academic Press.

[2] Allen, D.E., M. McAleer and A.K. Singh (2017), An entropy-based analysis of the relationship between the DOW JONES Index and the TRNA Sentiment series, Applied Economics, 49, 677-692.

[3] Barber, B.M., and T. Odean (2008), All that glitters: The effect of attention and news on the buying behaviour of individual and institutional investors, Review of Financial Studies, 21(2), 785-818.

[4] Cahan R., J. Jussa and Y. Luo (2009), Breaking news: How to use news sentiment to pick stocks, MacQuarie US Research Report.

[5] Da, Z.H.I., J. Engelberg, and P. Gao (2011), In search of attention, Journal of Finance, 66 (5), 1461-1499.

[6] diBartolomeo, D., and S. Warrick (2005), Making covariance based portfolio risk models sensitive to the rate at which markets react to new information. In J. Knight and S. Satchell. (Eds.), Linear Factor Models, Elsevier Finance.

[7] Dzielinski, M., M.O. Rieger, and T. Talpsepp (2011), Volatility asymmetry, news, and private investors, The Handbook of News Analytics in Finance (pp. 255-270), Wiley.

[8] Fuerriegel, S. and N. Pröllochs (2017), SentimentAnalysis, $\mathrm{R}$ package, available at https://cran.rproject.org/web/packages/SentimentAnalysis/index.html

[9] Hafez, P. and J. Xie (2012), Factoring Sentiment Risk into Quant Models, RavenPack International S.L

[10] Keynes, J.M. (1936), The General Theory of Employment, Interest and Money, Palgrave Macmillan, Basingstoke, UK.

[11] Mehrabian, A. (1981), Silent Messages: Implicit Communication of Emotions and Attitudes, Belmont, CA, Wadsworth.

[12] Mitra, L., G. Mitra, and D. diBartolomeo (2009), Equity portfolio risk (volatility) estimation using market information and sentiment, Quantitative Finance, 9(8), 887-895.

[13] Pröllochs, N., S. Fuerriegel and D. Neumann (2017), Understanding negations in information processing: Learning from replicating human behaviour, Working Paper, Information Systems Research, University of Freiburg, available at SSRN https://ssrn.com/abstract $=2954460$ 
[14] Reid, D.M. (1988), Marketing the political product, European Journal of Marketing, 22(9), 34-47.

[15] Swartz, T. (1973), The Responsive Chord, New York, Anchor Press/Doubleday.

[16] Tetlock, P.C. (2007), Giving content to investor sentiment: The role of media in the stock market, Journal of Finance, 62, 1139-1167.

[17] Tetlock, P.C., S.A. Macskassy, and M. Saar-Tsechansky (2008), More than words: Quantifying language to measure firms' fundamentals, Journal of Finance, 63, 1427-1467.

[18] Wiener, M, and A. Mehrabian (1968), Language within Language: Immediacy, A Channel in Verbal Communication, New York, Apple-CenturyCrofts. 